\title{
Um diálogo entre epistemologia, educação e pedagogia teatral
}

FÁBIO DA SILVA MOURA

CAROLINE CAREGNATO

Fábio da Silva Moura é Mestre em Letras e Artes pela Universidade do Estado do Amazonas (UEA) onde também cursou a graduação em Licenciatura em Teatro. Professor e Diretor teatral, trabalha atualmente com produção e gestão cultural no Amazonas. No campo científico, dedica-se na investigação sobre a cognição no campo das Artes, com ênfase nos temas: Epistemologia nas Artes, Ensino e Aprendizagem em Arte, Construção de conhecimento em Teatro, e Pedagogia Teatral.

Afiliação: Universidade do Estado do Amazonas

Lattes: <http://lattes.cnpq.br/9010743895970828>

Caroline Caregnato é Doutora em Música pela Universidade Federal do Paraná (UNICAMP) e Mestre em Música pela Universidade Federal do Paraná (UFPR). Possui graduação em Licenciatura em Música pela Escola de Música e Belas Artes do Paraná (EMBAP), e graduação em Educação Artística pela Universidade Federal do Paraná (UFPR). Atualmente é professora adjunta da Universidade do Estado do Amazonas. Tem experiência na área de Artes, com ênfase em Cognição Musical, atuando principalmente nos seguintes temas: cognição musical, teoria piagetiana e educação musical.

Afiliação: Universidade do Estado do Amazonas

Lattes: <http://lattes.cnpq.br/9638767577242874> 
- RESUMO

Transmitir? Libertar? Provocar? Esse trabalho vislumbra relacionar três correntes epistemológicas (ligadas aos questionamentos da frase anterior) com suas derivações dentro da educação e, mais especificamente, com o ensino do Teatro. Cada pressuposto epistemológico será acompanhado dos seus respectivos desdobramentos pedagógicos, formando "pares" entre teorias que, em síntese, serão empirismo/pedagogia diretiva, inatismo/pedagogia não-diretiva, e construtivismo/pedagogia construtivista. O texto nos ajuda a compreender as possibilidades de relação dessas teorias com o ensino de Teatro, bem como suas adequações ou inadequações. O trabalho ainda tece críticas aos paradigmas empirista e inatista, bem como às pedagogias a eles relacionadas, defendendo a adoção de uma perspectiva construtivista como embasamento para a prática do professor de Teatro. A pesquisa se trata de uma revisão de literatura e conta com a fundamentação oferecida por autores da Epistemologia, da Educação e da Pedagogia Teatral.

\section{PALAVRAS-CHAVE}

Correntes epistemológicas. Concepões pedagógicas. Pedagogia teatral..

\section{ABSTRACT}

To transmit? To freed? To provocate? This paper approaches three epistemological theories (linked to the questions of the first phrase) and their relations with theories in the area of education and, more specifically, with Drama teaching. Each epistemological assumption is going to be accompanied by its own pedagogical extension, creating "pairs" between theories that are, in synthesis, empiricism/directive pedagogy, innatism/non-directive pedagogy, and constructivism/constructivist pedagogy. The text helps us to comprehend the relations between those theories and Drama teaching, as well as their adequacies and inadequacies. The work also presents criticism to empiricist and innatist approaches, as well as the pedagogies related to them, defending the adoption of a constructivist approach as a basis for the practices of Drama teachers. The research involves a literature review and has the foundation offered by authors of Epistemology, Education and Drama Pedagogy.

\section{KEYWORDS}

Epistemological currents. Pedagogical conceptions. Drama pedagogy. 


\section{Introdução}

A discussão apresentada neste artigo está focada sobre o Teatro enquanto área do conhecimento, bem como sobre o seu ensino na educação formal e nãoformal. Para ensinar Teatro, é preciso que o professor domine conhecimentos específicos desta área, e que esse seja capaz de relacionar esses conhecimentos com saberes pedagógicos. Contudo, acreditamos que para um exercício profissional crítico o professor ainda precisa estar consciente das implicações epistemológias de suas práticas pedagógicas. A epistemologia é um ramo da filosofia que tem como pretensão estudar a origem, a permanência e a validade dos conhecimentos. É uma área concentrada em discutir como se constrói conhecimento. Falando etimologicamente, epistheme significa "verdade", logos, "conhecimento" e ia, "arte de" (FRANCO, 1998).

Todo posicionamento pedagógico implica em um ou mais posicionamentos epistemológicos, haja vista que a ideia de construção de conhecimentos é o centro de ambas áreas, pedagogia e epistemologia: enquanto uma (a epistemologia) busca compreender como se constrói conhecimentos, a outra (a pedagogia) pratica a construção de conhecimentos. Portanto, é importante que o professor tenha clareza sobre como se constrói o conhecimento em sua área de atuação, a fim de refletir sobre as escolhas pedagógicas (relativas a metodologias, objetivos, materiais didáticos, etc.) que o mesmo venha a tomar, sobre a pertinência destas para que ocorra a aprendizagem dos estudantes e também para que sejam respeitadas as características da área em que trabalha.

Neste artigo vamos discutir três concepções epistemológicas e suas derivações pedagógicas. Quando usamos o termo concepções pedagógicas nos referimos às ações e concepções que estão relacionadas ao ato de ensinar. Todas as atitudes tomadas pelos professores fazem parte de alguma concepção pedagógica, desde quando ele interfere diretamente no aprendizado, até ao outro extremo, quando ele se isenta completamente do seu papel docente. Assim, o termo concepções pedagógicas é utilizado neste trabalho em referência às diversas formas como a educação é observada, teorizada e praticada.

Dentre as teorias epistemológicas e pedagógicas que iremos discutir aqui estão, respectivamente, o empirismo e a pedagogia diretiva, o inatismo e a pedagogia não-diretiva, e o construtivismo (também nomeado "interacionismo") e a pedagogia construtivista. Essas correntes costumam supervalorizar em alguns casos o docente, os discentes ou a interação entre ambos. Essas concepções, traduzindo didaticamente, fazem avançar, retardar ou até mesmo impedir o processo de construção do conhecimento (BECKER, 2009). Ainda, como veremos, algumas correntes trazidas para o ensino de Teatro vão de encontro ao que se propõe atualmente dentro dos processos artísticos de criação e também dentro dos processos de ensino dessa linguagem, não se adequando mais ao contexto local, histórico e social em que ocorrem essas práticas.

Nosso objetivo é discutir em que medida cada uma dessas correntes pedagógicas e epistemológicas se adequa ou não às especificidades do ensino do Teatro, enquanto área de conhecimento, e em que medida elas podem favorecer a aprendizagem do estudante. Na sequência são apresentadas as três correntes 
epistemológicas mencionadas, seus diálogos com as concepções pedagógicas correspondentes e seus desdobramentos com relação à pedagogia do Teatro e ao fazer teatral.

\section{O empirismo/pedagogia diretiva e o ensino do teatro}

A pedagogia diretiva está relacionada com a epistemologia empirista, haja vista que essa corrente epistemológica acredita que o ser humano nasce sem conhecimentos, e por meio da intervenção do mundo, ou do contato com objetos e pessoas, os conhecimentos são introjetados no sujeito. Sendo assim, cabe ao professor agir de forma diretiva, oferecendo aos alunos as condições "ambientais" para que ocorra a sua aprendizagem, e os reforços ou recompensas para que elas se fixem (BECKER, 1994).

Um dos psicólogos mais importantes do pensamento empirista é Skinner (1904-1990), que dedicou grande parte de seus estudos para investigar o comportamento humano. Skinner (apud LEFRANÇOIS, 2015) acreditava que o conhecimento humano provém do meio em que o sujeito está inserido. Assim como todos os behavioristas radicais, ele colocou em segundo plano as análises sobre o "pensamento humano", ou sobre os sentimentos, pelo fato de esse ser um estudo imaterial, não-observável, incerto e demasiadamente amplo.

Por esta discussão podemos observar o quão pouco é adequado que um professor de Teatro se coloque com uma postura empirista, pois essa corrente epistemológica se contrapõe a diversas questões que essencialmente fazem parte do Teatro enquanto área de saberes. Sendo esta uma linguagem artística, valorizase assumidamente o seu potencial subjetivo, já que os envolvidos com o Teatro possuem experiências pessoais que dificilmente serão desassociadas de suas práticas artístico-pedagógicas.

Partindo do trabalho do ator para discutir a questão da subjetividade no Teatro, podemos tomar o caso da interpretação como concebida na perspectiva de Stanislavski (apud KUSNET, 1997). Segundo essa corrente, é impossível que o ator deixe de lado os aspectos emocionais inerentes à sua prática, pois na medida em que esse inicia um processo de criação de personagem, este se construirá por meio das experiências vividas pelo ator e suas memórias, em diálogo com as projeções das características de determinada personagem. Logo, para fazer Teatro de acordo com essa visão não se pode fazer "vista grossa" ao universo interno, não observável dos sujeitos, como sugerem os behavioristas radicais.

No campo do ensino de Teatro as dinâmicas não são muito diferentes, sendo fundamental o resgate de experiências subjetivas. No caso do jogo teatral, por exemplo, para Ramaldes (2017) a experiência é um dos seus fundamentos básicos, assim como no teatro improvisacional de Viola Spolin (2008). Na vida humana, as experiências são contínuas, e não são pontuais, pois não se encerram em si mesmas, sendo responsáveis por trazer elementos do passado individual e social do ser humano. Ainda, as experiências dos participantes não se limitam em coexistências isoladas, mas sim, precisam se relecionar ativamente, construíndo novas perspectivas e lançando diferentes olhares para cada situação apresentada. Não se faz Teatro individualmente. A sua realização necessita de diferentes pessoas atuando em diferentes funções. É preciso que ocorra um encontro de subjetividades. Mesmo 
que o espetáculo seja um monólogo, ainda assim haverá mais de uma pessoa, seja operando som e/ou luz, seja um produtor, seja o público. A ação teatral habita na relação humana ativa, portanto, sendo permeada pelo subjetivo, que não pode ser ignorado.

A pedagogia diretiva foi alvo de críticas, como as apresentadas por Freire (1987) em Pedagogia do Oprimido. Esse autor denominou o modelo em questão como "educação bancária", mas ele também utilizava termos como "pedagogia centralizadora", "pedagogia tradicional", "pedagogia tecnicista" entre outros que se referem, grosso modo, às práticas que consideram os estudantes como folhas em branco que devem ser "preenchidas" pelo professor.

Essa pedagogia coloca o professor como centro do conhecimento, como portador do saber, e os estudantes estão ali para serem "abastecidos" pelos conhecimentos daquele que é a autoridade da sala de aula (o professor). Becker (1994) discute sobre essa pedagogia e afirma: "penso que o professor age assim porque ele acredita que o conhecimento pode ser transmitido para o aluno" (ibid, p. 89). Essa frase possui uma ideia chave para o pensamento da pedagogia diretiva, que é o sentido de "transmissão de conhecimento", colocando o professor como proprietário do saber, e, por isso, como alguém que pode transmiti-lo para os estudantes.

Um exemplo da supervalorização da função do professor de Teatro pode ser percebido nos casos em que este profissional assume todas as escolhas basilares de uma construção cênica, como optar por uma dramaturgia já "fechada", designar suas preferências estéticas, conduzir uma montagem teatral a partir de ordens verticalizadas que diminuem os espaços para a criação por parte dos estudantes, como ocorre nas montagens teatrais mecanizadas que se vê muitas vezes na escola. Essas são algumas características da aplicação do conceito de educação bancária dentro da pedagogia teatral, as quais já sinalizam a inadequação desta base pedagógica.

As autoras Ferraz e Fusari (2009) falam na pedagogia tecnicista como herdeira da perspectiva diretiva, e dizem que quando ela é adotada nas aulas de Arte, principalmente nas de desenho, se valoriza a cópia fiel das imagens que o professor fornece. Os professores adeptos dessa corrente valorizam o traço, o contorno, a configuração, e o ensino é voltado, sobretudo, para o aprimoramento do conhecimento técnico. Não espera-se que o aluno crie, propriamente, ou se posicione criticamente diante daquilo que aprende, basta a reprodução de conhecimentos.

Essa discussão pode ser expandida para a questão da pedagogia do espectador $^{1}$. É possível perceber que entre as concepções cênicas mais discutidas estão aquelas que se desprendem dos aspectos ilusórios da produção teatral. Podemos mencionar como exemplo o Teatro épico de Brecht, que mesmo sendo formulado em 1920, influencia diretamente muitas produções cênicas contêmporaneas. Nessa perspectiva, o Teatro se desprende do caráter de puro entretenimento, e também rompe com a fantasia sustentada por aparatos técnicos como cochias, tapadeiras e bambolinas, deixando visível elementos como fios de iluminações e estruturas cenotécnicas.

\footnotetext{
${ }^{1}$ Entende-se como pedagogia do espectador as diversas formas com que os encenadores/professores de Teatro compreendem a relação entre palco-plateia (DESGRANGES, 2006).
} 
Desgranges (2005) afirma que o encenador no Teatro épico precisaria desvendar os mecanismos do palco e evidenciar os elementos da linguagem teatral, para que fosse possível traçar um diálogo explícito com o público. Essa visão formulada por Brecht visa aproximar ao máximo o espectador da encenação e, principalmente, da construção da encenação, para que os espectadores pudessem compreender os signos (des)construídos, e tornar mais íntima sua interação com a cena. Desgranges (2005, p. 04) afirma que:

\footnotetext{
O espectador do teatro épico poderia, assim, perceber-se como participante fundamental do evento, já que a cena se apresentaria aberta, colocando-se em franco diálogo com ele. O teatro passava a solicitar uma atuação efetiva do espectador, evidenciando para este que sem o cumprimento do ato produtivo, interpretativo que lhe cabe, o fato artístico não se completaria.
}

A perspectiva do Teatro épico assim como a grande maioria das encenações contemporâneas que se baseiam em conceitos deste olhar épico ou de outras fontes, reavaliam a necessidade de uma ação produtiva por parte dos espectadores e, ainda mais, uma ação interventiva destes sujeitos. Diante disso, podemos observar que nem mesmo os espectadores de Teatro possuem, na contemporaneidade, um papel passivo. Logo, por qual motivo a relação entre professor e aluno deveria ser passiva na prática pedagógica dessa linguagem artística? Assim como nos palcos, nas escolas os estudantes de Teatro também devem inserir suas potencialidades subjetivas e criativas dentro de sua prática e apreciação teatral. Essa necessidade coloca em xeque, portanto, a validade da perspectiva empirista na pedagogia teatral. A adoção de uma postura pedagógica diretiva ou empirista implica no estabelecimento de um descompasso, na construção de um caminho de contramão àquilo que propriamente é o Teatro dentro da contemporaneidade. Este tipo de ação não é adequada ao que se concebe atualmente no campo teatral, mesmo que as práticas baseadas na pedagogia diretiva sejam comuns em escolas tradicionais brasileiras, que às vezes contratam um profissional externo à escola para a realização de montagens de caráter mecanizado em datas comemorativas. O Teatro contemporâneo não se contenta mais com a imitação da realidade, ou com um papel passivo de quem assiste e de quem aprende essa área na escola.

\section{O inatismo/pedagogia não-diretiva e o ensino do teatro}

Na pedagogia não-diretiva o estudante é colocado como centro do processo de ensino e aprendizagem, e o desenvolvimento do conhecimento acontece de forma espontânea, de modo que os estudantes aprenderão sozinhos, por conta própria. Este modelo pedagógico se contrapõe ao apresentando anteriormente, haja vista que surgiu em meados do século XX como consequência das críticas voltadas à escola diretiva. A partir daquele período tomava corpo, então, um amplo movimento de reforma, cuja expressão mais típica ficou conhecida sob o nome de escola nova (SAVIANI, 2008). 
De acordo com Ferraz e Fusari (2009), diferente da escola tradicional e diretiva, que buscava trabalhar com o racional e o intelectual dos alunos, o escolanovismo valoriza as manifestações afetivas e sentimentais dos estudantes. Nesta perspectiva,"a ênfase é a expressão como dado subjetivo e individual que os alunos manifestam em todas as atividades, as quais passam de aspectos intelectuais para afetivos" (ibid, p. 45).

É possível ainda identificar algumas semelhanças entre essa pedagogia e as teorias freireanas e piagetianas, no momento em que se reconhece o sujeito (estudante) como portador de diversas formas de conhecimento. Por outro lado, a pedagogia não-diretiva se afasta desses autores pelo fato de supervalorizar um dos polos no processo de ensino e aprendizagem. Enquanto o modelo anterior (pedagogia diretiva) supervaloriza o papel do professor, este outro modelo supervaloriza a atuação do estudante no processo.

A pedagogia não-diretiva é associada à epistemologia inatista, para a qual o conhecimento já está pré-construído no sujeito. Aqui o "aluno já traz um saber, que ele precisa apenas trazer à consciência, organizar, ou ainda, rechear de conteúdo. O professor deve interferir o mínimo possível” (BECKER, 1994, p. 90). A pedagogia vinculada a essa epistemologia acredita que o aprendiz é o portador do conhecimento e que o professor deve agir na forma de "facilitador", sendo cauteloso nessa relação para que os aprendizes possam se desenvolver sozinhos.

Rogers (1902-1987) é um dos principais teóricos vinculados ao inatismo e à pedagogia não-diretiva. Para ele o termo ensinar está muito relacionado com o fato de instruir os alunos, com saber fazer: "ensinar é, a meu ver, atividade relativamente sem importância e enormemente supervalorizada" (ROGERS, 1975, p. 106). Ele ainda propõe que se quisermos promover alguma mudança no âmbito educacional, teríamos que ir além de ensinar, ultrapassando o modelo tradicional e facilitando a aprendizagem auto-iniciada. Nesse sentido, o único homem que se educa é aquele que aprendeu como aprender, que aprendeu como se adaptar e mudar e se convenceu de que nenhum conhecimento é seguro (ROGERS, 1975). O propósito do educador, ou facilitador, segundo Rogers (ibid, p. 107) é:

\footnotetext{
Libertar a curiosidade, permitir que as pessoas assumam os encargos de seguir em novas direções ditadas por seus próprios interesses, desencadear o senso da pesquisa, abrir tudo à indagação e à análise; reconhecer que tudo se acha em processo de mudança [...] Vejo a facilitação da aprendizagem como o fim da educação.
}

A facilitação de aprendizagem trabalha com a vontade dos sujeitos, visa proporcionar autonomia naqueles que deixaram o rótulo de alunos e passaram a ser chamados de aprendizes na teoria rogeriana. Nessa perspectiva não-diretiva, o processo que o aprendiz vivencia recebe o nome de aprendizagem significativa, que envolve os conteúdos que dialogam diretamente com os desejos dos aprendizes e com as suas necessidades. O não-diretivismo rogeriano tem sido atacado por autores como Franco (1998), que o acusam de negar uma cooperação legítima entre o estudante e o professor, ou dos estudantes entre si, uma vez que entende-se que o aluno deve "crescer sozinho" (ibid, p. 83). 
Dentro do ensino do Teatro, existem propostas que partem das vontades dos participantes, tendo a sua satisfação como principal preocupação. Esse é o caso, por exemplo, do jogo dramático, como proposto por Slade (apud KOUDELA; SANTANA, 2005), que afirma existir uma arte infantil e que coloca o jogo dramático como forma de equacionar as experiências pessoais e emocionais dos jogadores. "Dentre os muitos valores do jogo está o emocional, e Slade propõe que o jogo dramático forneça à criança uma válvula de escape, uma catarse emocional" (ibid, p. 148). Além de o jogo dramático se aproximar do que propõe a escola nova, como frisam Koudela e Santana (2005), ele também dialoga diretamente com aspectos inatistas, pelo fato de supervalorizar o desejo dos estudantes e direcionar o cerne da prática do ensino do Teatro a questões emocionais e de satisfação pessoal dos mesmos, colocando em segundo plano a aquisição de conhecimentos socialmente construídos, como é o caso dos conhecimentos teatrais propriamente ditos.

Apesar do diálogo existente entre a proposta de ensino de Teatro mencionada e a corrente inatista, veremos adiante que os jogos teatrais e dramáticos têm sido repensados por autores da contemporaneidade na direção de propostas mais complexas, que valorizam a construção de conhecimentos teatrais sem desconsiderar os sujeitos da aprendizagem e o conhecimento socialmente estabelecido.

\section{O construtivismo/pedagogia construtivista e o ensino do teatro}

A pedagogia construtivista defende que o processo de ensino-aprendizagem ocorre em conjunto entre o professor e o aluno, de modo que o professor planeja e compartilha as atividades com os alunos porque "ele acredita que o aluno aprenderá, construirá conhecimento novo, se ele agir e problematizar a sua ação" (BECKER, 1994, p. 92). Podemos destacar ainda que quando Becker (1994) usa a expressão "se ele agir e problematizar sua ação" não está se referindo necessariamente a ações práticas para aprender. É possível (e necessário) realizar ações em pensamento, que são as denominadas operações mentais (DELVAL, 1998). Portanto, para os construtivistas é importante que o aluno tenha participação ativa no processo de ensino e aprendizagem, mas que conte também com a mediação do professor, que não se exime de suas funções pedagógicas.

"O pressuposto epistemológico desse modelo pedagógico é o interacionismo, em que o sujeito constrói seu conhecimento" (BECKER, 1994, p. 93). A epistemologia interacionista, por vezes chamada de construtivista (assim como a corrente pedagógica), acredita que o ser humano ao nascer possui alguns saberes em sua herança genética, que são chamados de ações inatas ou reflexos, como por exemplo, chorar diante de uma necessidade biológica relativa à alimentação. Porém, todo o mais que o sujeito necessita para sua definitiva inserção no mundo dependerá de sua construção. O meio no qual o sujeito está inserido, sozinho, não é capaz de promover o desenvolvimento de que o sujeito necessita. A estrutura do sujeito (ou seja, a própria pessoa) precisa responder àquilo que o meio lhe apresenta, transformando-se em função do que lhe foi posto. Portanto, a perspectiva interacionista se diferencia da empirista pelo protagonismo que o sujeito adquire. Para a pedagogia que se baseia na epistemologia interacionista, o professor precisa contribuir para o processo de engajamento dos estudantes com relação aos conteúdos apresentados, para que o próprio estudante construa seus conhecimentos. 
Becker (1994) define duas etapas para que ocorra o processo de aprendizagem: "a) que o aluno aja (assimilação) sobre o material que o professor presume que tenha significado para o aluno; b) que o aluno responda para si mesmo às suas perturbações (acomodação) provocadas pela assimilação" (ibid. p. 92). Essas duas etapas correspondem à teoria de Piaget (1896 -1980) sobre o conceito de adaptação. Para Delval (1998), adaptação é o processo de modificação do organismo do sujeito visando adaptar-se ao meio. "Adaptação não é um processo passivo, mas ativo, o que significa que o organismo ao se adaptar, está se modificando, mas, ao mesmo tempo, modifica o meio" (DELVAL, 1988, p. 66).

Nesse sentido, o organismo se relaciona com o meio, transforma-o, modifica-o e, com o passar dos tempos, o próprio organismo se transforma e se reconstrói em função das informações que foram por ele construídas. Assim, o processo de adaptação é a transformação da estrutura do organismo, apropriando-se das provocações realizadas pelo meio em que está inserido (DELVAL, 1998). O pressuposto construtivista acredita que o mundo constrói o sujeito, na mesma medida que o sujeito constrói o mundo. A partir daí, entendemos que a relação de ensinoaprendizagem em Teatro, segundo a ótica interacionista, se dá de acordo com as interferências que o meio faz sobre o sujeito, mas também que o sujeito excerce sobre o meio em que está inserido.

O conhecimento em Teatro, assim como todo tipo de conhecimento, se dá na relação entre o professor e o estudante, ou entre os próprios estudantes, e a troca é um elemento essencial. A interação é proposta pelos construtivistas como importante ferramenta de aprendizagem porque o próprio contato com o outro e a escuta de visões diferentes já implica em aprendizagem, por mais que ao final do diálogo cada sujeito se mantenha com sua opinião ou visão original.

$\mathrm{Na}$ perspectiva da pedagogia do espectador proposta por Desgranges (2006), o fato de assistir um espetáculo teatral solicita do espectador um posicionamento ativo, pois a obra provoca o contemplador constantemente, convidando-o a decodificar e interpretar os signos apresentados em cena. Essa decodificação se constituirá quando o espectador ouvir e compreender a história em seus detalhes, e tomar uma atitude interpretativa a partir das suas próprias experiências, fomentando o seu pensamento crítico (DESGRANGES, 2006). Aí estão postas duas etapas do processo contemplativo de uma obra teatral, a primeira se trata do reconhecimento dos símbolos comunicados pela encenação, e posteriormente, ocorre a interpretação das informações com base em seus conhecimentos vivenciados no passado, para que, talvez, interfira ativamente em seu presente.

A ambiguidade das informações presente em uma mesma obra faz com que ela seja recebida de maneiras diferenciadas, mas esse não é o único fator que faz uma obra receber várias interpretações. Não podemos agrupar todos os espectadores uma categoria única. Cada sujeito recebe uma obra a seu modo porque cada um possui experiências de vida diferenciadas. Para ser finalizado, o acontecimento artístico se completa quando o espectador constrói a sua relação com a obra e seu processo criativo, agindo quase como um coautor da criação (DESGRANGES, 2006).

Como afirma Glasersfeld (2003), o ato de considerar a opinião do outro se constitui em um ato de construir dentro do próprio pensamento uma visão sobre a realidade até então não ponderada. Se entendermos, como, aliás, compreendem os construtivistas, que a realidade não é um dado objetivo, que está pronto "fora" do 
sujeito, mas sim que ela é algo que precisa ser construído na mente de cada um de nós, o próprio ato de ouvir e considerar uma opinião divergente já implica uma atividade de construção da realidade, ou seja, de transformação da própria estrutura de pensamento (atividade de adaptação) e, portanto, em um gesto de aprendizagem. Além disso, a interação é frequentemente entendida como uma fonte de perturbação, ou de provocação do desequilíbrio cognitivo, que resulta na consciência de se saber desconhecedor de algo e que é o motor para a busca de novas aprendizagens (GLASERSFELD, 1989). É por essas razões que se valoriza tão fortemente a interação dentro dessa perspectiva pedagógica, interação esta desvalorizada pelas correntes discutidas anteriormente, que colocavam no centro o professor ou o aluno, sem que houvessem trocas efetivas entre eles.

Nesse sentido, é papel do professor agir como um "problematizador" (FRANCO, 1998). Ou seja, ele deve organizar a interação do estudante com os conteúdos através de problematizações e provocações, para que o próprio estudante construa seu conhecimento a partir dessa mediação. O aluno não pode ser abandonado à própria sorte, como sugerem os não-diretivistas, apenas porque o conhecimento deve ser construído por ele mesmo. Usando a linguagem metafórica de Glasersfeld (2003) - sem que estejamos querendo sugerir uma caracterização grosseira dos personagens - o trabalho do professor é semelhante ao do fazendeiro com seu cão, quando guia um grupo de bois por uma estrada e precisa garantir que os animais não se desviem do caminho. O cão segue à frente trancando passagens, evitando que os animais pulem cercas, enquanto o fazendeiro segue garantindo que os bois marchem em frente. A linguagem que o professor utiliza com seus alunos cumpre papel semelhante ao do cão: ela não pode transmitir conhecimentos. Por meio das suas intervenções o professor apenas pode buscar garantir que o estudante não se desvie da estrada e se mantenha em marcha, mas o curso não deixa de ser percorrido por quem aprende, assim como o caminho não deixa de ser triIhado pelos próprios animais da metáfora.

Dentro da pedagogia do Teatro existe uma metodologia que vem sendo relacionada cada vez mais aos conceitos construtivistas. Essa metodologia é o jogo teatral, concebido pela americana Spolin (2008) que, por sua função simbólica, vem dialogando com questões da representação e do desenvolvimento da linguagem. Algumas vezes pode-se confundir o jogo dramático (sobre o qual falamos anteriormente) com o jogo teatral, mas,

Spolin estabelece uma diferença entre o jogo dramático e o jogo teatral, diferenciando assim a sua proposta para um Teatro improvisacional de outras abordagens, através da ênfase no jogo de regras e no aprendizado da linguagem teatral (KOUDELA; SANTANA, 2005, p. 147).

Existem outras questões que diferenciam os conceitos de jogos dramáticos e jogos teatrais. Enquanto o jogo dramático ${ }^{2}$, na perspectiva de Pupo (2005), está mais relacionado a questões de externalização de fantasias subjetivas ${ }^{3}$, o jogo tea-

\footnotetext{
2 Importante mencionar que o conceito de "jogo dramático" é alvo de constantes acepções sobre o seu significado, e não existe uma verdade absoluta acerca deste tema.

3 Cabe reiterar um aspecto peculiar a essa abordagem da dramatização: o termo jogo dramático serve aqui para designar tanto 0 ato de fazer de conta, espontâneo na criança pequena, quanto uma modalidade de atuação coletiva que resulta da intervenção deliberada do adulto, visando à diversificação e ao enriquecimento da ação de caráter ficcional (PUPO, 2005).
} 
tral se preocupa em evitar a ação irrefletida, se preocupa com conhecimentos específicos do Teatro, e com o estabelecimento de regras dentro de suas atividades. Neste sentido, o jogo teatral se caracteriza como uma ação problematizada ou provocada pelo instrutor do jogo, que vai ao encontro da estrutura dos sujeitos, provocando sua reconstrução à medida que os sujeitos modificam a situação do jogo, caracterizando-se, assim, como uma prática construtivista. Portanto, o professor não se ausenta do processo de ensino e aprendizagem, mas age ativamente, como um problematizador, como alguém que provoca o desenvolvimento dos estudantes.

No jogo teatral, como Koudela expõe no prefácio para o livro de Spolin (2008), os problemas cênicos ainda são resolvidos em coletivo, e as regras do jogo estabelecidas em negociação travada entre os jogadores. Segundo Koudela e Santana (2005), no jogo teatral, pelo processo de construção da forma estética, a criança estabelece com as outras uma relação de trabalho em que a fonte da imaginação criadora - o jogo simbólico - é combinada com a prática e a consciência da regra de jogo, a qual interfere no exercício artístico coletivo. Portanto, o jogo teatral é uma metodologia que privilegia a interação entre pares, a atividade coletiva, o contato entre pensamentos divergentes, dialogando novamente com o que propõe o interacionismo como forma de construção de conhecimento.

O jogo teatral ainda se diferencia do jogo dramático por ser acompanhado por uma avaliação, que pode ser realizada pelos próprios estudantes a partir das provocações do professor, ao término da atividade. Koudela e Santana (2005) defendem que a intervenção do coordenador de jogo é fundamental ao desafiar o processo de aprendizagem e de reconstrução de significados dos estudantes. As propostas de avaliação do coordenador de jogo deixam de ser retrospectivas, para se transformarem em prospectivas. A avaliação passa a ser propulsora do processo de aprendizagem, e não se contenta em acusar sucessos ou fracassos passados, como ocorre com a avaliação da pedagogia diretiva.

Assim sendo, os próprios alunos são levados a refletirem sobre o que "funcionou" ou não na proposta realizada, buscando soluções mais efetivas, sem necessitar dos apontamentos sobre certo ou errado fornecidos unilateralmente pelo professor. Desse modo, a proposta dialoga novamente com os pressupostos do construtivismo, para o qual a correção dos erros deve ser realizada pelo próprio estudante, uma vez que quando os equívocos são apontados pelo professor o aluno é privado da oportunidade de se conscientizar sobre a inadequação das respostas que foram oferecidas, bem como sobre o motivo dessa inadequação e sobre quais seriam as melhores alternativas a serem tomadas. Quando o professor aponta os erros e, mais, aponta também a resposta correta, o estudante simplesmente aceita o que the foi dito, sem que tome consciência da verdadeira necessidade daquilo. $O$ prazer de chegar a uma resposta certa por conta de seus próprios esforços ainda motiva o estudante a seguir aprendendo. O professor construtivista também aceita 0 erro do estudante e deixa que ele se manifeste, pois essa é uma importante oportunidade para que o educador se dê conta do modo como pensa seu aluno, podendo a partir disso construir estratégias de ação pedagógica mais efetivas (GLASERSFELD, 1989).

Continuando essa discussão, podemos observar que Koudela e Santana (2005) sugerem que o jogo teatral é pensado de modo a respeitar a estrutura da 
criança e aquilo de que ela é capaz em diferentes momentos, ao mesmo tempo que visa promover o seu desenvolvimento. Nesse sentido, os autores apontam as transformações que o jogo sofre ao longo do desenvolvimento infantil, baseando-se na teoria piagetiana e demonstrando consciência sobre os processos internos que conduzem a aprendizagem. Dessa forma, a proposta do jogo teatral dialoga com os pressupostos construtivistas, pois, de acordo com Franco (1998), o professor adepto dessa corrente deve conhecer não apenas a realidade "exógena" dos seus alunos, buscando adequar suas propostas pedagógicas ao entorno social, cultural, histórico, etc. em que vivem seus estudantes, gerando a aprendizagem significativa a que se referiam mesmo os não-diretivistas. É importante ainda que o professor tenha consciência da realidade "endógena" dos sujeitos, ou seja, ele deve ter consciência dos processos "invisíveis" (mas indiretamente observáveis) que acontecem no pensamento do estudante, e sobre os seus desdobramentos ao longo do desenvolvimento, pois suas propostas pedagógicas também devem respeitar e valorizar essa realidade interna do aluno, para que seja promovido o seu desenvolvimento efetivo.

Pelo que viemos expondo até aqui, fica evidente que o construtivismo se distancia das propostas não-diretivas e inatistas. Ccontudo, o construtivismo também se distancia do diretivismo ou do empirismo, uma vez que estes negam, como discutimos, as atividades mentais não observáveis de pensamento ou reflexão. Para o behaviorismo o que importa é a ação, de modo que o pensamento, ou a compreensão, segundo as palavras de Skinner (apud GLASERSFELD, 2003, p. 178, tradução nossa) são uma "ficção mental, pré-científica". O construtivismo, pelo contrário, privilegia uma educação voltada para a compreensão, para o desenvolvimento do pensamento crítico, em lugar de focar no treinamento de habilidades (GLASERSFELD, 1989).

Nesse sentido, os pressupostos construtivistas conseguem dialogar, por exemplo, com as proposições artistico-pedagógicas do Teatro Épico de Brecht, que ao longo de 30 anos, organizou uma nova percepção de relacionamento entre a obra e o público, assumindo um Teatro que tornava visível as suas próprias engrenagens, e negava o caráter ilusionista do Teatro dramático. Para Desgranges (2006, p. 41), o "Teatro Épico brechtiano estruturava-se como uma pedagogia do espectador, tendo em vista que este poderia fruir mais prontamente o espetáculo à medida que conhecesse melhor o aparato constituinte de uma encenação". O foco desse Teatro era a democratização de conhecimentos teatrais, pois na medida em que os espectadores conheciam novas informações, eles ampliavam seu repertório linguístico e estético e, ainda, eram convidados a se posicionarem diante dos acontecimentos apresentados a partir de suas experiências vividas.

O público do Teatro Épico passou a ter sua participação estimulada pelo próprio discurso cênico, pois Brecht intensificou esse diálogo que a cena propõem à plateia. Para Desgranges (2006, p. 45), "a arte teatral deveria despertar sua atividade, proporcionando-lhe conhecimentos advindos da reflexão sobre o que está sendo apresentado em cena. $\mathrm{O}$ espectador estaria sendo contraposto à ação e não transportado para dentro dela". Por exemplo, a dramaturgia no Teatro Épico é essencialmente construída como a narração de um fato já ocorrido com uma terceira pessoa, fortalecendo o distanciamento entre a figura do narrador (e do autor) do mundo representado, assim também como distancia a realidade do espectador das 
imagens postas em cena devida a incompatibilidade temporal da estrutura narrativa. Para Desgranges (2006, p. 55), "o palco era oferecido como espaço relevante para o debate das questões que afligiam as nossas sociedades, e os espectadores convidados a participarem efetivamente desses eventos". O Teatro se tornou um importante espaço de fortalecimento imagético e de influência sociopolítica, sendo assim, um espaço de interação entre as experiências das pessoas, no qual o conhecimento é construído na ação/reflexão, e não na passividade. Logo, como dizíamos, a proposta de Brecht está em sintonia com os pressupostos construtivistas de engajamento e participação ativa dos sujeitos na construção de suas visões de mundo, ou de seu conhecimento.

O construtivismo ainda dialoga, como apontado por Concilio (2009), com o processo colaborativo enquanto processo de construção teatral. Conforme o autor, em uma montagem construída nesses moldes a direção, a dramaturgia, os cenários, etc., possuem uma autoria bem definida, mas são elaborados coletivamente "por meio de debates, construções de consensos ou votações e foram sendo definidos a partir de um processo largamente elaborado junto a todos os integrantes envolvidos no processo" (CONCILIO, 2009, p. 2). Não há, portanto, uma imposição de pontos de vista, de conhecimentos ou de desejos. O que há é uma construção que se dá na interação, como propõe o construtivismo e também a pedagogia de projetos (de inspiração construtivista), que é "uma pedagogia que lança perguntas, ao invés de impor pontos de vista e professar respostas" (ibid), ou seja, uma pedagogia que demanda o envolvimento efetivo dos sujeitos com o processo de construção do conhecimento. Novamente, observamos que o construtivismo se articula com as práticas contemporâneas do Teatro mais fortemente que as demais correntes pedagógicas ou posturas epistemológicas.

\section{Últimas considerações}

Assim como toda área específica de ensino-aprendizagem, o Teatro possui diversas possibilidades de construção de conhecimento, pautadas em diferentes metodologias. Koudela e Santana (2005, p. 147) nos afirmam que "há várias abordagens metodológicas para o Teatro na educação, que nasceram de forma independente, em contextos culturais e educacionais diversos e em grande parte estranhos uns aos outros".

Cabe ao professor, diante dessa diversidade de opções de atuação pedagógica, escolher e construir seus caminhos. Em função disso, compreender como pode ocorrer a construção de conhecimentos em sala de aula é essencial para o trabalho do professor de Teatro. Discussões como as apresentadas aqui podem o ajudar a pensar e repensar em possibilidades de atuação. A inconsciência sobre essas questões pode interferir negativamente nas suas ações.

Diante dos pressupostos pedagógicos e epistemológicos apresentados, podemos perceber que ao adotar uma postura empirista o professor pode impedir ou retardar a construção de conhecimento teatral, haja vista que esse pressuposto é contrário a diversos posicionamentos do Teatro e da Pedagogia Teatral por menosprezar a subjetividade.

A corrente inatista apresenta algumas relações com o ensino do Teatro pelo 
fato de valorizar o papel do aprendiz e colocar suas escolhas em evidência. Por outro lado, a competência pedagógica nessa corrente é desvalorizada, e o professor de Teatro não pode interferir, nem provocar o aprendiz, o que novamente se torna inviável quando se trata da aprendizagem de um conhecimento, como o teatral, que não é "natural", dado aos sujeitos desde o seu nascimento, mas sim que é fruto de práticas social e historicamente construídas e que precisam se dar a conhecer.

Já a última epistemologia apresentada (construtivista) é, na nossa opinião, a que mais se aproxima de uma relação ideal de ensino-aprendizagem em Teatro, pelo fato de permitir ao educador uma posição interventiva, mas, principalmente, ao educando um aspecto ativo, pautado na ação-reflexão, configurando-se em uma prática que dialoga com os princípios do Teatro e da pedagogia teatral discutidos na atualidade.

\section{REFERÊNCIAS}

BECKER, Fernando. A Epistemologia do Professor: o cotidiano da escola. 11ed. Petrópolis, Editora Vozes, 2009.

Modelos Pedagógicos e Modelos Epistemológicos. Porto Alegre, v. 19 n. 1: p. 89-96, jan.

1994.

CONCILIO, Vicente. Elementos para uma possível relação entre pedagogia do teatro e processos colaborativos de criação teatral. In: REUNIÃO CIENTÍFICA DE PESQUISA E PÓS-GRADUAÇÃO EM ARTES CÊNICAS, 5, 2009, São Paulo. Anais... São Paulo: USP, 2009. p. 1 - 5. Disponível em: <file://C:/Users/Qbex/Downloads/2645-7580-1-SM.pdf>. Acesso em: 24/07/2019.

DELVAL, Juan. Crescer e Pensar: a construção de conhecimento na escola. Porto Alegre: Artes Médicas, 1998.

DESGRANGES, Flávio. A Pedagogia Teatral de Brecht: o teatro épico. São Paulo: Hucitec, 2005.

Pedagogia do Teatro: Provocação e Dialogismo. São Paulo: Hucitec, 2006.

FERRAZ, Maria Heloísa C. de T.; FUSARI, Maria F. de Resende. Metodologia do ensino de arte: fundamentos e proposições. 2 ed. São Paulo: Cortez, 2009.

FRANCO, Sérgio Roberto Kieling. O Construtivismo e a Educação. 8 ed. Porto Alegre: Mediação, 1998.

FREIRE, Paulo. Pedagogia do Oprimido. 17ed. Rio de Janeiro: Paz e Terra, 1987.

GLASERSFELD, Ernest von. Cognition, construction of knowledge, and teaching. Synthese, vol. 80, n. 1, p. 121-140, 1989. DOI: https://doi.org/10.1007/BF00869951

Radical Constructivism: a way of knowing and learning. London: Routledge Falmer, 2003.

KUSNET, Eugênio. O Ator e o Método. Rio de Janeiro: Funarte, 1997. 
LEFRANÇOIS, Guy R. Teorias da Aprendizagem. São Paulo: Cengage Learning, 2015.

PUPO, Maria Lúcia Barros. Para desembaraçar os fios. Educação \& Realidade. Rio Grande do Sul, v.30, n.2, p. 217-228, 2005.

RAMALDES, Karine. Os Jogos Teatrais de Viola Spolin: uma pedagogia da experiência. Goiânia: Kelps, 2017.

ROGERS, Carl R. Liberdade para Aprender. Belo Horizonte: Interlivros, 1975.

SAVIANI, Dermeval. Escola e Democracia. Campinas: Autores Associados, 2008.

SPOLIN, Viola. Jogos Teatrais para a Sala de Aula: um manual para o professor. São Paulo: Perspectiva, 2008.

Recebido em 14/04/2018 - Aprovado em 23/06/2019

Como citar:

Moura, F. da S.; Caragnato, C. (2019). Um diálogo entre epistemologia, educação e pedagogia teatral. OuvirOUver, 15(2), 482-496. https://doi.org/10.14393/OUV-v15n2a201941614

cc) (7) (8) A revista ouvirOUver está licenciada com uma Licença Creative EY Commons Atribuição-NãoComercial 4.0 Internacional. 